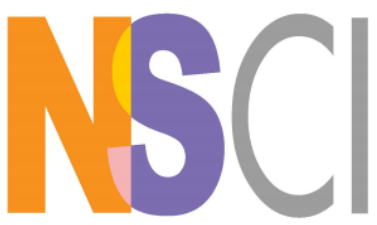

Current Perspectives on Medicinal and Aromatic Plants

An International Journal

ISSN: 2619-9645 | e-ISSN: 2667-5722

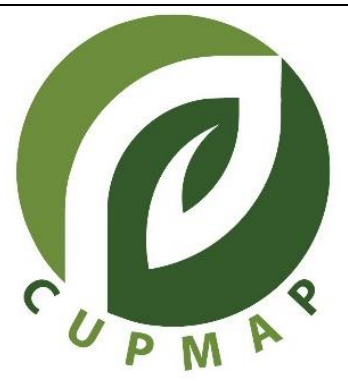

\title{
Antimicrobial, Antibiofilm-forming Properties of Equisetum arvense L. Shoot Extracts
}

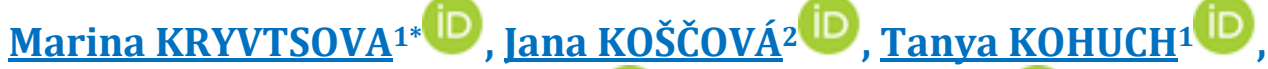 \\ Marianna SAVENKO ${ }^{1}$ (D), Nokolay SPIVAK $^{3}$ (iD) \\ 1Department of Genetics, Plant Physiology and Microbiology, F aculty of Biology, \\ Uzhhorod National University, Postal code 88000, Uzhhorod, Ukraine \\ ${ }^{2}$ Department of Microbiology and Immunology, \\ University of Veterinary Medicine and Pharmacy in Košice, Postal code 04181 Košice, Slovakia \\ ${ }^{3}$ D.K. Zabolotny Institute of Microbiology and Virology of NAS of Ukraine, 154, Zabolotny str., \\ Postal code 03143, Kyiv, Ukraine \\ *Corresponding author: maryna.krivcova@gmail.com
}

\begin{abstract}
Under the current conditions of growing antibiotic resistance of microorganisms, studies of antimicrobial properties of natural substances, including those obtained from medicinal plants, acquire special interest. The future outlook of such studies is caused by the fact that the resistance of microorganisms to vegetablebased substances may develop much slower or may not develop at all. This work is devoted to investigation into antimicrobial, antibiofilm-forming and some phytochemical properties of Equisetum arvense L. extracts. The results of the study showed high antibiofilm-forming activity of Equisetum arvense L. extracts exemplified by Staphylococcus biofilm. Antimicrobial properties of the reviewed extracts were also ascertained. Antibacterial activity was identified against typical and clinical antibiotic-resistant bacterial strains isolated from the mouth cavity of patients suffering from inflammatory processes. High antioxidant activity of the extracts was shown. A set of properties, in particular the antimicrobial and antibiofilmforming activity, high content of tannins and antioxidant activity, shows good prospects to include horsetail (Equisetum) extracts in the oral cavity care plan.
\end{abstract}

Key Words: Extracts of medicinal plants, antimicrobial effect, antibiofilm-forming activity

(C) CUPMAP. All rights reserved.

\section{Introduction}

Under the present-day conditions of growing antibiotic resistance of microorganisms, studies aimed at searching for natural, including plant-based, substances with antimicrobial activity acquire special importance. This trend is related to the variety of biologically active compounds having a broad spectrum of pharmacological effect, antioxidant, anti-inflammatory and even antitumour activities (Gezici \& Sekeroglu, 2019). Plant-based substances have been widely used in conventional and folk medicine, food, pharmaceutical and beauty industries. Studies aimed at searching for the antimicrobial active substances that are at the same time able to destroy bacterial biofilm have become of 
special interest. The microorganisms of the biofilm are known to be more resistant to antimicrobial preparations and an additional pathogenicity factor (O'Toole et al., 2000; Kalemba\&Kunicka, 2003). This issue is especially important for oral cavity diseases, where most pathogens of inflammatory diseases are contained in the form of biofilm which complicates the treatment of persisting inflammatory diseases (Shunmugaperumal, 2010). In our previous works, we indicated to high percentage of antibiotic-resistant bacterial strains in oral cavity microbial associations affected by chronic inflammatory process (Kryvtsova \& Kostenko, 2018; 2019). Against the background of complicated clinical course of the inflammatory processes, Staphylococcus spp. genus bacteria and Staphylococcus spp.+Candida spp.; Staphylococcus spp. + Enterobcteriacese spp. associations were the dominating associants (Kryvtsova \& Kostenko, 2018; Kryvtsova, 2019). In [Sidashenko, 2015], it was also shown that biofilm microorganisms are characterized by a higher level of resistance to antimicrobial preparations. Therefore, searching for substances with complex antimicrobial and antibiofilm-forming effects has become of particular interest (Kryvtsova at al., 2019; Piegerová, 2019; Rhos \& Recio, 2005).

The objective of this work was to investigate into the antimicrobial, antibiofilm-forming, antioxidant and certain biochemical properties of Equisetum arvense L. shoot extracts.

\section{Material and Methods}

\subsection{Collection of Plant Material}

The plant material was collected in the vicinity of the village of Luta, Zakarpatska oblast (Trancarpathia), dried at the temperature of $30-35^{\circ} \mathrm{C}$ in shadow, then ground and placed in tightly closed containers.

\subsection{Preparation of Plant Extracts}

Ethyl and methyl extracts of of Equisetum arvense L. were made. A $10 \mathrm{~g}$ batch of the dry plant material was pulverized to powdery mass. In an Erlenmeyer flask, $10 \mathrm{~g}$ of the plant material were blended with 200 $\mathrm{ml}$ of or $96^{\circ}$ ethyl or methyl alcohol (Sigma, Germany). The opening was closed with a food wrap to avoid evaporation. Following a 30-minute-long incubation in the ultrasonic bath (Kraintek) at $35^{\circ} \mathrm{C}$, the blend was filtered through Whatman No. 1 filter paper. The clear solution was placed in an evaporative device (16-17/32" x 34-59/64" G5B, Coated Dry Ice Condenser Rotary Evaporator) to obtain pure alcoholic extract at $50{ }^{\circ} \mathrm{C}, 82 \mathrm{rpm}$. Then, extracts were exposed to evaporation under reduced pressure at $40{ }^{\circ} \mathrm{C}$ in order to remove ethyl or methyl.

\subsection{Antimicrobial Activity}

The antibacterial activity of the studied extracts was assessed by the minimum inhibitory concentration (MIC) coefficient [Rhos \& Recio, 2005]. To study the MICs of the plant extracts, the following solutions in beef-extract broth were produced: $100 ; 50$; $25 ; 22.5 ; 20 ; 17.5 ; 15 ; 12.5 ; 10 ; 7.5 ; 5 ; 3.5$; 2.5 ; and $2.25 \mathrm{mg} / \mathrm{ml}$. The bacterial suspension was introduced into each testtube in the amount of $100 \mu \mathrm{l}$, which corresponded to 0.5 McFarland standard $\left(1.5 \times 10^{8} \mathrm{CFU} / \mathrm{ml}\right)$ from a 24-hour culture of microorganisms in sterile physiological solution. The test-tube was incubated for 24 hours at $37{ }^{\circ} \mathrm{C}$, whereupon part of the contents of each test-tube was inoculated 
into the beef-extract broth. The last testtube, whose inoculations did not show any growth of the microbial culture, was taken as the MIC. The negative controls were the following: bacterial suspension + dimethyl sulfocide; bacterial suspension + alcohol.

As test cultures, the following bacteria and yeasts from the American Type Culture Collection were used: Candida albicans ATCC 885-653; Staphylococcus aureus ATCC 25923; Escherichia coli ATCC 25922; Enterococcus faecalis ATCC 29212; Streptococcus pyogenes ATCC 19615; and as reference - S. aureus CCM CCM 4223 biofilmforming strain. We also used clinical strains of bacteria and yeasts ( $S$. aureus, E. coli, $S$. pyogenes, E. faecalis, C. albicans) isolated from the oral cavities of patients suffering from inflammatory periodontium and pharynx diseases. We chose clinical strains with multiple resistance to at least two classes of antibiotics. As a positive control, the following were used: gentamicin (10 $\mathrm{mg} /$ disk) for Gram-negative bacteria, ampicillin (10 mg/disk) for Gram-positive bacteria, and nystatin (100 UI) for Candida. As negative control, DMSO were used.

\subsection{Determination of Antibiofilm Activity}

With the purpose of studying the antibiofilm formation activity, an 18-hour culture of the reference $S$. aureus CCM 4223 grown at $37{ }^{\circ} \mathrm{C}$ was used. Into the wells, $180 \mu \mathrm{l}$ of bacterial suspension, McFarland in broth (Tryptic soy broth (TSB), Himedia, India) were introduced. The Vaccinium vitis-idaea $L$. leaves and berries extracts were adjusted to the concentrations of $1 \%, 5 \%$ and $10 \%$ in DMSO (Sigma-Aldrich, USA) and introduced into the wells in the amount of $20 \mu \mathrm{l}$ per well. Upon the addition of the bacterial suspension, the concentrations of plant extracts in the broth were equal to $0.1 \%$,
$0.05 \%$ and $0.01 \%$, respectively. The wells with only $180 \mu \mathrm{l}$ of broth and $20 \mu \mathrm{l}$ of $10 \%$ DMSO served as control. Following a 24hour incubation in the thermostat at $37^{\circ} \mathrm{C}$, the supernatant was withdrawn and washed 3 to 5 times with distilled water. Following a 30-minute incubation, it was dyed with 200 $\mu \mathrm{l}$ of $0.1 \%$ solution of crystal violet; then the dye was withdrawn, and the supernatant was washed 3 to 5 times with distilled water. Into every well, $200 \mu \mathrm{l}$ of $30 \%$ acetic acid were added and incubated for 10 minutes. Optical density was measured on the Synergy HT (Biotek, USA) spectrophotometer at $550 \mathrm{~nm}$. The mean absorbance $\left(\mathrm{OD}_{550 \mathrm{~nm}}\right)$ of the samples was determined, and the percentage inhibition obtained using Eq.1. (Sandasi et. al., 2011).

Negative controls: $180 \mu \mathrm{l}$ of bacterial suspension $+20 \mu \mathrm{l}$ of alcohol (ethyl or merthyl, respectively); $180 \mu \mathrm{l}$ of suspension $+20 \mu \mathrm{l}$ of dimethyl sulfocide. When a $50 \%$ reduction in absorbance was observed, it was considered as significant inhibition.

\subsection{Antioxidant Activity}

The antioxidant activity of extracts of medicinal plants and essential oils was identified by means of spectrophotometric 2-diphenyl-1-picrylhydrazyl free radical (DPPH•) scavenging method (Blois, 1958). The antioxidant activity was expressed as percentage $(\%)$ of the scavenging activity. Trolox was used for comparison. The optical density of the mixture was identified spectrophotometrically with the use of a Spectrophotometer Beckman Coulter DU 530 following $30 \mathrm{~min}$. of incubation at the wavelength of $515 \mathrm{~nm}$. The percentage of DPPH radical scavenging activity was calculated by using the following formula: 


$$
\begin{aligned}
& \text { DPPH radical scavenging activity (\%) } \\
& =\frac{\text { Abs (control) }- \text { Abs }(\text { sample })}{\text { Abs (control) }} \times 100
\end{aligned}
$$

where Abs (control): Absorbance of DPPH radical + methanol; Abs (sample): Absorbance of DPPH radical + extract.

\subsection{Determination of Tannins}

Tannins were determined spectrophotometrically (Galavo et. al., 2018) with the use of a Folin-Ciocalteu reagent. The optical density was measured at $750 \mathrm{~nm}$ (A), using the Beckman Coulter DU 530v spectrophotometer (USA); water was used as the solution for comparison. The percentage of tannins was expressed compared with the activity of pyrogallol [Medini et al., 2014].

\subsection{Determination of the Total Amount of Flavonoids}

The flavonoid content was determined by absorption spectrophotometry. For quantitative determination, spectrophotometric methods based on the measurement of absorption of the aluminium chloride and flavonoids complex was used. The quantitative content was recounted into rutin, and simultaneously the absorption of the standard rutin solution (the comparison solution) was measured. The total amount of flavonoids was determined by aluminium chloride spectrophotometric method [Medini et al., 2014]. The optical density was determined on the Beckman Coulter DU 530 spectrophotometer.

\subsection{Laboratory Base for Research}

The microorganisms from the oral cavities of patients with chronic periodontium inflammatory processes were isolated on the basis of the Dental Polyclinics, Uzhhorod National University; the extracts were manufactured and their antioxidative activity and contents of tannins and flavonoids were determined on the basis of the Department of Pharmacognosy and Botany, University of Veterinary Medicine and Pharmacy in Košice, Slovakia; the antimicrobial activity of plant extracts was studied at the Microbiological Laboratory of the Department of Genetics, Plant Physiology and Microbiology, Uzhhorod National University, and Department of Microbiology and Immunology, University of Veterinary Medicine and Pharmacy in Košice.

\subsection{Statistical Analysis}

The obtained data were expressed as mean \pm standard deviation (SD) of three measurements. The Tukey's test was applied for comparisons of means; the differences were considered significant if $\mathrm{p}<0.05$.

\section{Results and Discussion}

\subsection{Antibiofilm-Forming Antimicrobial Effects of Extracts} and

Equisetum arvense L. extracts demonstrated high destruction ability against the biofilm formed by S.aureus. In case of $0.1 \%$ concentration, the ethyl extract reduced the process of biofilm formation by $95.90 \%$; the methyl extract - by $69.86 \%$ (Fig. 1-2). In case of $0.05 \%$ concentration, the reductions were $77.8 \%$ for the ethyl extract, and $69.38 \%$ for the methyl extract. A substantial antibiofilm-forming effect was ascertained even for $0.01 \%$ extracts: the ethyl extracts reduced the biofilm-forming process by $63.0 \%$, and the methyl extract - by $48.72 \%$. The studies showed the antimicrobial activity of horsetail extracts against Gram- 
positive and Gram-negative microorganisms. The extracts demonstrated higher activity against reference strains than clinical ones (see Table 1).

E. arvense has been well known for high contents of bioactive components, like phenolic compounds, saponins, aconite, oxalic and malic acids, tars, tannins, pectin, flavones, vitamin $\mathrm{C}$, carotenoids and mineral substances [Jackson 1995; Pallag et al., 2018]. There are data about antimicrobial properties of Equisetum arvense extracts. In [Pallag et al., 2018], it was shown that Equisetum arvense L. demonstrated antibacterial effect upon pathogenic Grampositive cocci, though it did not affect Gramnegative bacteria and $C$. albicans. Literary sources provide information on antimicrobial activity of $1 \mathrm{~g} / \mathrm{ml}$ concentrations of horsetail methyl extract against S. epidermidis та E. coli, but no effect upon C. albicans was observed. This extract also showed antimicrobial activity against $K$. pneumoniae, $P$. aeruginosa and S. enteritidis. The antimycotic effect of horsetail extract was ascertained against A. niger. [Aldaas, 2011; Yoshinobu, 1992]. In [Wojnicz et al., 2012], an antimicrobial effect of $E$. arvense extracts upon E.coli was established. $E$. arvense extracts that had an antimicrobial effect upon coliform bacterium had three flavonoids and phenolic acids (protocatechuic, ferulic and caffeic acids). Our studies ascertained the antistaphylococcus and antibiofilm-forming activities of field horsetail extracts. For the first time, the antibiofilm-forming effect of horsetail extracts upon the biofilm formed by Staphylococcus aureus was shown. This ability may be used for biofilm destruction to improve the bioavailability of antimicrobial drugs.

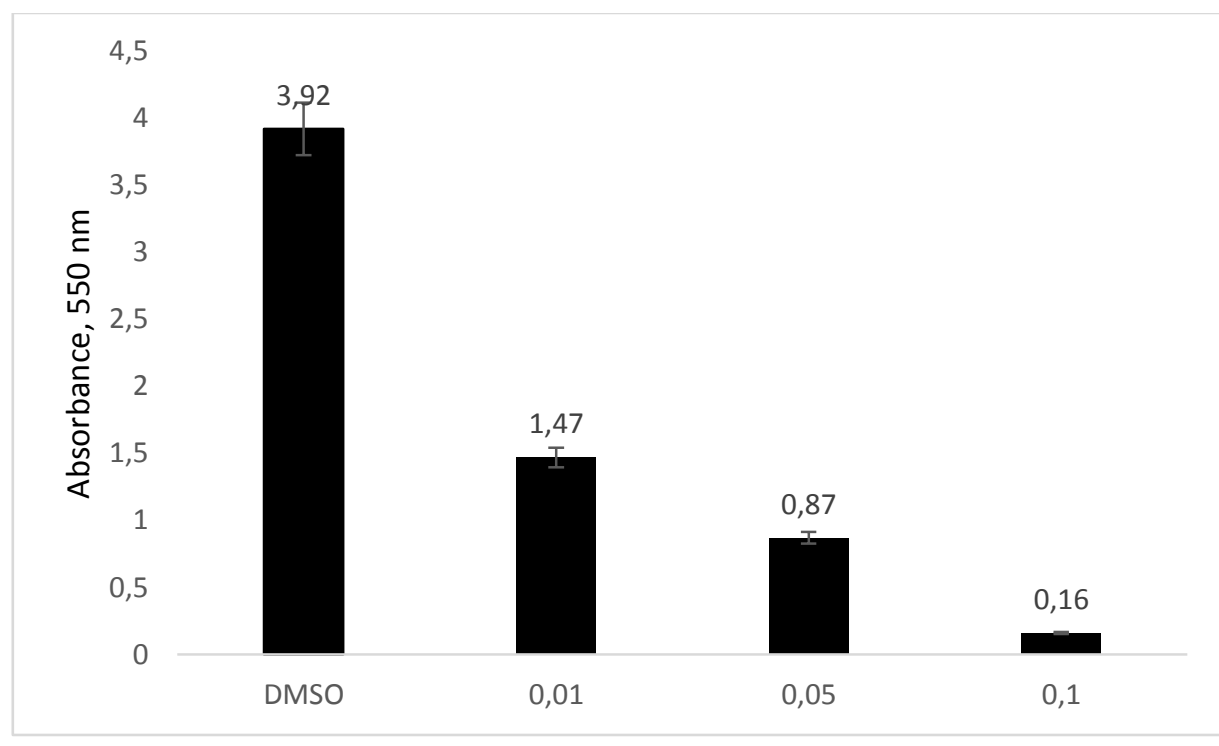

\section{Optical density}

Figure 1. Impact of Equisetum arvense L. ethyl extract upon the formed S. aureus biofilm. Control: S. aureus suspension in broth + dimethylsulfoxide were taken as $100 \%$ and used as control (OD = $3.82 \pm 0.2), \mathrm{n}=3$ 


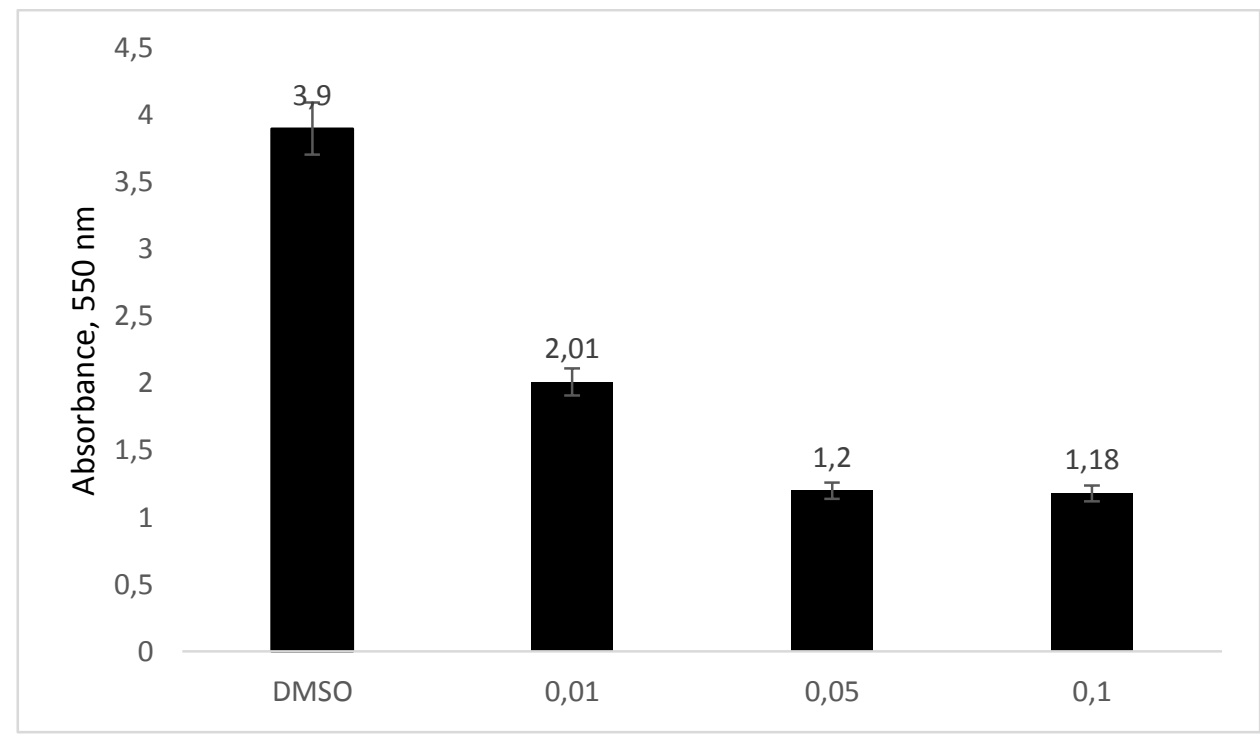

Figure 2. Impact of Equisetum arvense L. methyl extract upon the formed S. aureus biofilm Control: S. aureus suspension in broth + dimethylsulfoxide were taken as $100 \%$ and used as

$$
\text { control (OD = 3.82 } \pm 0.2), \mathrm{n}=3
$$

Table 1. Antimicrobial effect of ethyl and methyl extracts of Equisetum arvense L. shoots against reference and clinical bacterial strains, $\mathrm{mg} / \mathrm{ml}, \bar{x} \pm S D$

\section{Test cultures}

S. aureus ATCC 25923

S. aureus clinical strains

E. coli ATCC 25922

E. coli clinical strains

E. faecalis ATCC 29212

E. faecalis clinical strains

S.pyogenes ATCC 19615

S.pyogenes clinical strains

\section{Minimum inhibit concentration}

\begin{tabular}{cc}
\hline Ethyl extract & Methyl extract \\
\hline $7,33 \pm 0,13^{\mathrm{d}}$ & $15,5 \pm 0,5^{\mathrm{c}}$ \\
$15,5 \pm 0,5^{\mathrm{b}}$ & $20,58 \pm 0,8^{\mathrm{a}}$ \\
$15,5 \pm 0,25^{\mathrm{b}}$ & $15,5 \pm 0,25^{\mathrm{c}}$ \\
$12,58 \pm 0,8^{\mathrm{c}}$ & $15,41 \pm 0,52^{\mathrm{c}}$ \\
$12,67 \pm 0,29^{\mathrm{c}}$ & $12,67 \pm 0,29^{\mathrm{d}}$ \\
$5,42 \pm 0,38^{\mathrm{e}}$ & $5,25 \pm 0,43^{\mathrm{e}}$ \\
$17,5 \pm 0,5^{\mathrm{a}}$ & $17,5 \pm 0,5^{\mathrm{b}}$ \\
$16,00 \pm 1,30^{\mathrm{b}}$ & $17,5 \pm 0,76^{\mathrm{b}}$ \\
\hline
\end{tabular}

The control: 1) extracting solvent (ethanol) - no inhibition zone; 2) solvent (dimethylsulfocide) - no inhibition zone; the data differ statistically significantly as compared with the control - ethanol and dimethylsulfocide

\subsection{Phytochemical Screening of Antioxidant Activity}

The extracts were shown to be characterized by a high level of tannins and antioxidant activity (Table 2). The high antioxidant activities combined with the antimicrobial activity and high antibiofilm-forming effects lay behind the prospects of the use of horsetail extracts as part of oral cavity care plans. The literature mentions the modulating effect of Equisetum arvense L. extract upon endothelial cells that submit to the influence of the hypertonic environment. The experimental data have proved that if applied in low doses, Equisetum arvense L. may become a new therapeutic approach to lower the heightened oxidative stress and hypertonicity-related apoptosis (Pallag, 2018). 
Table 2. The level of tannins and flavonoids, and the antioxidant activity of ethyl and methyl extracts of Equisetum arvense $\mathrm{L}$. shoots, $\%$

\begin{tabular}{cc}
\hline Ethyl extracts & Methyl extracts \\
\hline \multicolumn{3}{c}{ tannins } \\
\multicolumn{2}{c}{ flavonoids } \\
$0.95 \pm 0.06$ & $0.70 \pm 0.3$ \\
\multicolumn{2}{c}{ antioxidant activity } \\
$78.10 \pm 0.5$ & $74.88 \pm 1.0$ \\
\hline
\end{tabular}

\section{Conclusions}

Our research has shown the antimicrobial activity of Equisetum arvense $L$. ethyl and methyl extracts upon antibiotic resistant strains of Staphylococcus genus bacteria. These trends were shown both on typical and clinical strains that were isolated from the oral cavities of patients suffering from chronic diseases of oral cavity and characterized by high antibiotic resistance. High antibiofilm-forming activity of Equisetum arvense L. ethyl extract was established. A significant antioxidant activity of the reviewed extracts was shown. The obtained results indicated to good prospects for further research aimed at development of horsetail-based preparations for oral cavity care, because they, unlike chemical preparations, as a rule, have no side effects but have an astringent effect and antioxidant properties. Equisetum arvense $\mathrm{L}$. is an especially valuable vegetative material as it has for a long time been used in ethnic pharma medicine.

\section{Acknowledgements}

Authors would like to thank to. Uzhhorod National University.

\section{Conflicts of Interest}

The author declares no conflict of interest.

\section{Author Contribution Statements}

Marina KRYVTSOVA conceived and designed the experiments. Jana KOŠČOVÁ performed the experiments. Tanya KOHUCH supervised the research activity and setup methodology of experiment. Marianna SAVENKO wrote the paper and Nokolay SPIVAK contributed to writing the paper.

\section{References}

1. Aldaas, S., (2011). Cytotoxic and antibacterial activity of an extract from a Saudi traditional medicinal plant Equisetum arvense. MSc thesis, King Abdullah University of Science and Technology, Thuwal, 45-46. DOI:10.25781/KAUST-85V93

2. Blois, M. S., 1958. Antioxidant Determinations by the Use of a Stable Free Radical. Nature, 181:1199. 1200

3. Djeridane, A., Yous, M., Nadjemi, B., Boutassouna, D., Stocker, P., et al. (2006). Antioxidant activity of some Algerian medicinal plants extracts containing phenolic compounds. Food Chemistry, $97 \quad(4), \quad 654-660$. DOI:10.1016/i.foodchem.2005.04.028

4. Galvão, M. A., Arruda A. O, Bezerra, I. C., Ferreira, M. R., Soares, L. A. (2018). Evaluation of the FolinCiocalteu method and quantification of total tannins in stem barks and pods from libidibiaferrea (Mart. ex Tul) L. P. Queiroz. Brazilian Archives of Biology and Technology, 61, e1817058. DOI:10.1590/1678-4324-2018170586

5. Gezici, S., Şekeroğlu, N. (2019). Current Perspectives in the Application of Medicinal Plants Against Cancer: Novel Therapeutic Agents. Anticancer agents in medicinal chemistry, 19(1), 101111. DOI:10.2174/1871520619666181224121004

6. Jackson, B., P. (1995). Herbal drugs and phytopharmaceuticals: A handbook for practice on a scientific basis, edited and translated from the second German edition by Norman Grainger Bisset, London; Medpharm Scientific Publishers, Stuttgart, 10(5), 337.

7. Kalemba, D., Kunicka, A. (2003). Antibacterial and Antifungal Properties of Essential Oils. Current Medicinal Chemistry, 10(10), 813-829. DOI: $10.2174 / 0929867033457719$

8. Kryvtsova, M., V., Kostenko, Ye.,Ya. (2020). Dominant microbial associations of the oral cavity in the conditions of generalized periodontitis and features of there sensitivity to antibacterial drugs. 
Studia Biologica, 14(1), 51-62. DOI:10.30970/sbi.1401.613

9. Kryvtsova, M., V., Kostenko, Ye.,Ya., Salamon, I. (2018). Compositions of essential oils with antimicrobial properties against isolates from oral cavities of patients with inflammatory diseases of parodentium. Regulatory Mechanisms in Biosystems, 9(4), 491-494. DOI: $10.15421 / 021873$

10. Kryvtsova, M., V., Trush, K., Eftimova, J., Koščová, J., Spivak, M.J. (2019). Antimicrobial, antioxidant and some biochemical properties of Vaccinium vitisidea L. Mikrobiolohichnyi Zhurnal, 81 (3), 40-52. DOI:10.15407/microbiolj81.03.040

11. Kryvtsova, M.V. (2019). Microscopoc Candida genus fungi in the structure of microbial associations in the condition of generalized periodontitis and their sensitivity to antibiotics and essential oils. Bulletin of Problems Biology and Medicine, 1(2), 263-266. DOI:10.29254/2077

12. Medini, F., Fellah, H., Ksouri, R., Abdelly, C. (2014). Total phenolic, flavonoid and tannin contents and antioxidant and antimicrobial activities of organic extracts of shoots of the plant Limonium delicatulum. Journal of Taibah University for Science, $8(3), \quad 216-224$. DOI:10.1016/j.jtusci.2014.01.003

13.0”Toole, G.A. (2011). Microtiter dish biofilm formation assay. Journal of vsualized experiments, 47. DOI: $10.3791 / 2437$

14. O'Toole, G., Kaplan, H., B., Kolter, R. (2000). Biofilm formation as microbial development. Annual Reviews in Microbiology, 54, 49-79. DOI:10.1146/annurev.micro.54.1.49

15.Pallag, A., Filip, G.,A., Olteanu, D., Clichici, S., Baldea, I., et al. (2018). Equisetum arvense L. Extract Induces Antibacterial Activity and Modulates Oxidative Stress, Inflammation, and Apoptosis in Endothelial Vascular Cells Exposed to Hyperosmotic Stress. xidative Medicine and Cellular Longevity. Hindawi Limited, 3060525. DOI:10.1155/2018/3060525

16.Piegerová, A., Koščová, J., Schusterová, P., Nemcová, R., Kryvtsova, M. (2019). In vitro inhibition of biofilm formation by Staphylococcus aureus under the action of selected plant extracts. Folia Veterinaria, 63(1), 48-53. DOI:10.2478/fv2019-0007

17. Ríos, J. L., Recio, M. C. (2005). Medicinal plants and antimicrobial activity. Journal of ethnopharmacology, 100(1-2), 80-84. DOI:10.1016/i.jep.2005.04.025

18. Shunmugaperumal, T., 2010. Biofilm-Related Infections in the Oral Cavity. Biofilm Eradication and Prevention, 184-225. DOI:10.1002/9780470640463.ch7.

19.Sandasi, M., Leonard, C. M., Van Vuuren, S. F., \& Viljoen, A. M. (2011). Peppermint (Mentha piperita) inhibits microbial biofilms in vitro. South African Journal of Botany, 77(1), 80-85. DOI:10.1016/j.sajb.2010.05.011

20. Sidashenko, O., I., Voronkova, O.,S., Sirokvasha, O., A., Vinnikov, A. I. (2015). Exhibition pathogenicity factors in biofilm-forming and nobiofilm-forming strains of Staphylococcus epidermidis. Mikrobiolohichnyi Zhurnal, 77(2), 33-37. DOI: $10.15407 /$ microbiolj77.02.033

21.Wojnicz, D., Kucharska, A.,Z., SokolLetowska, A. (2012). Medicinal plants extracts affect virulence factors expression and biofilm formation by the uropathogenic Escherichia coli. Urological Research, 40(6), 683-697. DOI: 10.1007/s00240-012-0499-6

22. Yoshinobu, Y. (1992). Antitumor activity of crude protein extracted from Equisetum arvense LINN'E. Journal of Analytical Bio-Science, 22, 421-424. 